\title{
MODERNISMO NO ENSINO MÉDIO: INTERPRETAÇÕES DO BRASIL
}

\author{
AGUIAR, Denise Brasil Alvarenga ${ }^{1}$ \\ FREITAS, Adriana Maria Almeida de ${ }^{2}$
}

Leitura que provoca a ação de pensar e sentir criticamente as coisas da vida e da morte, os afetos e suas dificuldades, os medos, sabores e dissabores; que permite conhecer questões relativas ao mundo social e às tantas e tão diversas lutas por justiça.

(Sônia Kramer)

\section{RESUMO:}

Na busca de rever conteúdos e procedimentos didáticos em torno do ensino específico do Modernismo em turmas de ensino médio, o trabalho propõe uma abordagem da representação da brasilidade - um dos aspectos mais caros a esse período literário no país - que supere as tradicionais dicotomias traçadas a partir de comparações com o passado literário, especialmente com o Romantismo. Partindo da hipótese de que, para além da mera rejeição do passado, o Modernismo pavimentou uma trilha de redescoberta seletiva da história, desvelando relações de poder e fraturas dos projetos das elites brasileiras desde os tempos coloniais, espera-se contribuir para uma formação mais ampla do leitor no espaço escolar e, ainda, abrir possibilidades de construção de projetos interdisciplinares.

PalaVRas-Chave: Modernismo - Ensino Médio - Nacionalidade.

\section{ABSTRACT:}

Searching to review contents and didactic procedures concerning the particular teaching of Modernism for Brazilian high school students, this study proposes an approach to the representation of the brazilianess - one of the most remarkable aspects of this literary period in this country - which overcomes the traditional dichotomies designed from comparisons to the literary past, especially the Romanticism. Starting from the hypothesis that, besides the mere rejection of the past, Modernism has found the path to a selective discovery of history, revealing

\footnotetext{
${ }^{1}$ Licenciada em Letras Vernáculas (Português- Literaturas de Língua Portuguesa) pela UFRJ; mestre em Letras pela UFRJ; doutora em Letras pela UFF. Professora adjunta do Instituto de Aplicação da UERJ e da Faculdade de Educação da UFF. Coordenadora de Língua Portuguesa e Literatura do PIBID-UFF. E-mail: denisebrasilaa@yahoo.com.br ${ }^{2}$ Licenciada em Letras Vernáculas (Português- Literaturas de Língua Portuguesa) pela UFRJ; mestre em Letras pela UFRJ; doutora em Letras pela UERJ. Professora adjunta do Instituto de Aplicação da UERJ e do Mestrado Profissional do Colégio Pedro II. E-mail: amafreitas@uol.com.br
} 
power relations and the Brazilian elite project fragmentations since the colonial times, we hope to contribute to a comprehensive formation of the reader in the school context and to open possibilities of building interdisciplinary projects.

KEY WORDS: Romanticism - Brazilian High School - Nationality.

Há bastante tempo o Movimento Modernista ocupa lugar de destaque nos materiais didáticos voltados para o ensino de Literatura no ensino médio, chegando, inclusive, a figurar, junto com o Romantismo, como estilo central de um dos vestibulares no Rio de Janeiro ${ }^{3}$, em detrimento de todos os outros períodos históricos de nossa produção literária. Tamanho destaque justificase por muitas razões: da qualidade inegável de obras que se transformaram em cânones à sua importância histórica para a intelectualidade brasileira, várias seriam as possibilidades de explicação para esse fato.

Não nos interessa aqui questionar ou mesmo relativizar essa centralidade das produções modernistas no ensino de Literatura nas escolas, até porque partilhamos bastante dessa seleção. O sentido do presente artigo está centrado na busca da revisão crítica de um dos eixos tradicionais desse ensino: a questão da nacionalidade e de sua representação literária. $O$ que apresentamos, então, parte de nossa inquietude como professoras de Literatura, pela constatação de algumas banalizações significativas feitas nos livros didáticos e pela própria experiência de leitura partilhada de textos e debate de questões com nossos estudantes.

Na dinâmica própria de ensino e pesquisa que a atuação em um colégio de aplicação acaba impondo, percebemos como insuficientes as elaborações encontradas em

\footnotetext{
${ }^{3}$ Referimo-nos ao concurso de acesso aos cursos de graduação da UFRJ, que, por vários anos, selecionou esses dois estilos como focos dentro do processo literário brasileiro.
}

materiais didáticos, incrivelmente repetidores dos mesmos textos, das mesmas ideias, das mesmas intertextualidades. Sempre opondo Romantismo e Modernismo, considerando ambos monoliticamente, frequentemente fazendo um uso genérico de palavras como "crítica", "ruptura", "reação" etc, a despeito das nuances, dos desencontros, das desarmonias entre autores e modos de interpretar o Brasil em ambos os movimentos. Esse tipo de compreensão excessivamente dualista, que sequer faz jus à tradição pluralista do nosso Modernismo, nos é trazido tanto pelos estudantes, que são livres para consultar materiais disponíveis em livros ou na internet, quanto por estagiários, que por vezes ainda conservam muito dos modos de ensinar literatura que aprenderam a valorizar, ainda como alunos, na educação básica.

Se é compreensível que parte da crítica literária tenha cristalizado tais modelos de interpretação, até por força das declarações e sinalizações efetivamente feitas pelos primeiros modernistas - em seu desejo de propagandear a nova arte voltada contra as tradições -, é fato também que, passados quase cem anos, é preciso buscar compreender melhor as razões desse fenômeno cultural. Na tarefa de formação de leitores dos textos e do mundo, julgamos necessário aprofundar a reflexão sobre as raízes e desdobramentos dos anúncios de ruptura modernistas, buscando entender movimentos históricos que marcaram a sociedade brasileira da época, atravessada, como também hoje, por importantes desigualdades e desequilíbrios. 
Do ponto de vista do ensino, acreditamos que a mera reprodução das oposições entre Romantismo e Modernismo, no tocante à representação do nacional, traz o risco do reducionismo, um obstáculo para o letramento literário do estudante do ensino médio, tal como previsto nos PCN e citado ainda pelas Orientações Curriculares Nacionais para o Ensino Médio, em relação aos conhecimentos de Literatura:

Para cumprir com esses objetivos, entretanto, não se deve sobrecarregar o aluno com informações sobre épocas, estilos, características de escolas literárias, etc., como até hoje tem ocorrido, apesar de os PCN, principalmente 0 $\mathrm{PCN}+$, alertarem para o caráter secundário de tais conteúdos: 'Para além da memorização mecânica de regras gramaticais ou das características de determinado movimento literário, o aluno deve ter meios para ampliar e articular conhecimentos e competências que [...]" (BRASIL, PCN+, 2002, p. 55). Trata-se, prioritariamente, de formar o leitor literário, melhor ainda, de "letrar" literariamente o aluno, fazendo-o apropriar-se daquilo a que tem direito (OCNEM, BRASIL, 2006, p.54).

No atendimento a essas orientações que nos parecem, em essência, corretas para o ensino de literatura - , é preciso ir além do que se encontra, via de regra, nos materiais e procedimentos didáticos tradicionalmente adotados nas escolas. Uma possibilidade, na qual investimos e que expomos a seguir, é voltar o estudo das representações da brasilidade, temática central do nosso Modernismo, para a compreensão das diversas interpretações do Brasil, que, em plena "Era dos Extremos" (nas palavras de Hobsbawn), disputavam concepções e se aliavam a projetos diversos para o país.

Conjugados com um estudo dessa natureza, pensamos ainda ser possível cons- truir, nas escolas, projetos interdisciplinares, especialmente com outras disciplinas da área de ciências humanas e artes, em torno de questões como identidade, pluralidade cultural, pertencimento, nacionalidade, nacionalismo, autoritarismo etc. Trata-se, portanto, não apenas de uma via de revisão do ensino de literatura, mas da abertura de caminhos para alternativas pedagógicas que possam extrapolar os limites das disciplinas e mesmo do espaço confinado das salas de aula.

Buscamos, por ações coerentes com o que se encontra brevemente apontado aqui, nos articular com um viés de trabalho que, a exemplo do que sugere Sônia Kramer, pesquisadora evocada na epígrafe, compreenda a leitura como experiência, no sentido benjaminiano do termo:

Defendo a leitura da literatura, da poesia, de textos que têm dimensão artística, não por erudição. Não é o acúmulo de informação sobre clássicos, sobre gêneros ou sobre estilos, escolas ou correntes literárias que torna a leitura uma experiência, mas sim o modo de realização dessa leitura: ela deve ser capaz de engendrar uma reflexão para além do momento em que acontece, ser capaz de ajudar a compreender a história vivida antes e sistematizada ou contada nos livros (KRAMER, 1999, p.21).

\section{INTERPRETAÇÕES DO BRASIL}

Precisamos adorar o Brasil. Se bem que seja difícil caber tanto oceano e tanta solidão

no pobre coração já cheio de compromissos... se bem que seja difícil compreender o que querem esses homens, por que motivo eles se ajuntaram e qual a razão de seus sofrimentos.

("Hino Nacional", Carlos Drummond de Andrade) 
Na citadíssima conferência de 1942 "o movimento modernista" - Mário de Andrade avalia a direção assumida pela Semana de 22 , que a diferenciava qualitativamente dos outros momentos de manifestação de certa autonomia de pensamento no país:

A novidade fundamental, imposta pelo movimento, foi a conjugação dessas três normas num todo orgânico da consciência coletiva. E si, dantes, nós distinguimos a estabilização assombrosa de uma consciência nacional num Gregório de Matos, ou, mais natural e eficiente, num Castro Alves: é certo que a nacionalidade deste, como a nacionalistiquice do outro, e o nacionalismo de Carlos Gomes, e até mesmo de um Almeida Júnior, eram episódicos como realidade do espírito. E em qualquer caso, sempre um individualismo (ANDRADE: 1974, pp. 242-3).

A reflexão de Mário firma uma espécie de divisor de águas, pois a Semana não só se projetava para o futuro, pela declaração de um elemento programático explicitamente vinculado ao nacional coletivo, como também lançava olhar crítico para a tradição que a antecedera. Desse sentido programático, serão particularmente importantes tanto o senso de ação deliberada e coletiva reivindicada pelos participantes da Semana, os ironicamente ditos "Dragões do Centenário" - quanto o "racha" ideológico que adviria entre os modernistas, expresso no debate do tema do nacional (embora não restrito a ele).

Como uma parte fundamental da vocação parodística do primeiro momento do Modernismo volta-se para a reconsideração das questões ligadas à identidade nacional, conforme já foi amplamente debatido e estudado, é desnecessário esmiuçar aqui tudo o que se disse acerca do resgate ou da e- mergência dos elementos sufocados pelo processo de colonização e de dominação política, econômica e cultural; da inserção do humor como força destruidora de uma visão congelada do passado brasileiro; dos vários mecanismos de desritualização do nacional. Na busca de compreender dadas redes de interlocução, interessam, sobretudo, as posturas gerais - estéticas mas também políticas - dos modernistas acerca de uma tradição cultural na qual, até então, a inteligência brasileira vinha conseguindo discernir alguma forma de identidade, uma formação e um modo de ser partilhados pelos membros da nação.

De fato, a releitura crítica e subversiva do passado e da tradição vai constituir um dos pilares importantes de manifestação das posturas estéticas que então se consolidaram em torno do tema da brasilidade. O processo de formação cultural e social do Brasil é revisto por escritores como Oswald de Andrade, na forma de um conjunto de fragmentos que, orientados pelo humor, compõem uma crítica em mosaico sobre o olhar do colonizador.

Também o indianismo é objeto de intensa crítica, pelas feições europeizantes que the teriam imprimido os românticos. A fala de Oswald, no Manifesto Antropofágico, "contra o índio de toucheiro", "filho de Maria, afilhado de Catarina de Médicis e genro de D. Antônio de Mariz", representa a contracorrente da aculturação, a rejeição do índio romântico, que, para o modernista, era incapaz da atitude antropofágica de deglutição e, por isso mesmo, tributário do peso da civilização cristã ocidental.

A cadeia de grilhões ideológicos e culturais ainda não superados pela independência política, de fato, ainda se fazia presente no cenário político e cultural em que se moviam os primeiros modernistas brasileiros. Afinal, estes certamente se depara- 
vam com a necessidade de dar combate, por exemplo, aos ecos do ufanismo de um Afonso Celso, vigente nos primeiros anos do século $\mathrm{XX}$, que operava a paz dos espíritos por meio de uma promessa de futuro garantida pelas qualidades da terra e das três raças originárias.

Mas, para além das claras orientações de recusa das versões mais oficiais ou conservadoras, o projeto de construção da brasilidade continuava em aberto e colocava-se como tarefa para os "moços" modernos, que, em grande medida, a enfrentarão exatamente pela revisão do já feito, pela busca do que se perdeu no caminho. Romper com os sentidos homogêneos que a tradição privilegiara era passo necessário para desenvolver um outro olhar sobre o Brasil, sua cultura e sua sociedade.

Por isso, as imagens da colonização e do Romantismo ganham destaque, por evocarem momentos nos quais mais agudamente se expressaram interpretações que concorreram para aquilo que há muito tempo se compreendia como cultura brasileira, nacional. A natureza, a catequese, o domínio branco, o percurso do índio contado sempre pela voz do outro, todos comparecem à chamada crítica das obras e manifestos do período. Assim, é significativo o fato de que tais interpretações submeteram-se, sob a batuta modernista, ao sentido da superação e da ruptura, que tanto animou os espíritos da Semana.

É verdade que o olhar sobre o passado e a tradição se fará sob uma intenção de ruptura, que marcará não só o seu fundamental, como também alguns dos passos posteriores daqueles que buscarão identificar-se com o ímpeto criativo e crítico modernista. "Romper" e "inaugurar" serão vocábulos que, no século $X X$, frequentarão 0 imaginário de muitos como sinônimo de refletir e criar, obliterando sinais de tensão como o emitido por Mário de Andrade, no "Prefácio Interessantíssimo"- "Sou passadista, confesso. Ninguém pode libertar-se duma só vez das teorias-avós que bebeu...".

Essa direção específica do olhar para o passado manifesta-se, nos discursosplataforma da época, de diversas formas, a partir de posicionamentos que, naquele momento, buscavam afunilar-se na perspectiva do encontro para o combate aos tradicionalistas. Já na abertura da Semana, a conferência de Graça Aranha anunciava, em tom de desafio e irônica ameaça:

(...) Não está terminado o vosso espanto. Outros "horrores" vos esperam. Daqui a pouco, juntando-se a esta coleção de disparates, uma poesia liberta, uma música extravagante, mas transcendente, virão revoltar aqueles que reagem movidos pelas forças do Passado. Para estes retardatários a arte ainda é o Belo (in: TELES: 1983, p. 280).

Essa atmosfera viera, na verdade, sendo forjada desde antes da deflagração do movimento modernista, marcado pelo evento da Semana, conforme já demonstraram vários estudiosos e pode ser fartamente comprovado por um rápido exame do material crítico da época. Em janeiro de 1921, por exemplo, Menotti del Picchia publicava no Correio Paulistano o artigo "Na maré das reformas", no qual expõe grande parte das ideias motrizes de 22, inclusive a orientação disseminada quanto à tradição romântica:

O pensamento nas suas fórmulas objetivas deve acompanhar passo a passo a mutação protéica da luta humana; Casimiro de Abreu não pode, com seu lirismo romântico, cantar a agitação das greves, nem Alencar, indianizado, descrever a paixão das mulheres vestidas de seda e dos homens vorazes, de garras aduncas e olhar de gerifalte (in: BRITO, 1974, p. 189). 


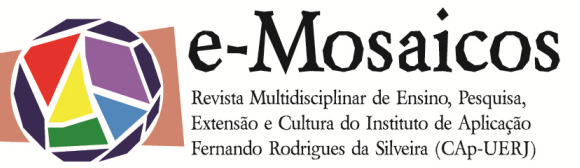

$\mathrm{O}$ ataque à tradição justificava-se, então, não só pelo que ela encobria de opressor, mas por sua completa inadequação à análise e representação dos agitados tempos modernos do início do século XX. Mas esse ataque, prioritário e em muito referenciado nas conquistas das vanguardas estrangeiras, não se fez desligado de uma reflexão sobre as relações entre a arte e o conjunto de fraturas sociais do Brasil - aliás em evidência na década de 20 , com a ascensão do movimento urbano dos trabalhadores e da insatisfação das camadas médias expressas principalmente pelo tenentismo.

Vários dos manifestos que sucederam a Semana trazem esse diálogo. Drummond, por exemplo, no editorial de $A$ Revista, em 1925, fala do momento da vida republicana brasileira, no qual se assistia "ao espetáculo quotidiano e pungente das desordens intestinas, ao longo das quais se desenha, nítida e perturbadora, em nosso horizonte social, uma tremenda crise de autoridade", delegando à mocidade a tarefa de reagir, sempre segundo as exigências do atual estágio da civilização, o que requeria uma nova atitude (in: TELES: 1985, p. 337).

Com o signo do novo ditando o fundamental do perfil da chamada primeira fase do Modernismo brasileiro, a tradição incluindo as formulações sobre o nacional haveria de ser, naturalmente, submetida a uma revisão crítica que contemplasse as inquietudes próprias da época. O problema da importação cultural - em evidência junto com seu correlato econômico da dependência externa - emerge como algo a ser reapropriado por uma postura nova, que se afaste definitivamente daquela matriz de um olhar sempre estrangeiro - não mais necessariamente o português, tendo em vista um longo ciclo de outras influências no século
XIX e mesmo o sentido mais amplo que o agressivo imperialismo da época impunha.

Graça Aranha, em conferência de 1924, contrapõe-se ao academicismo e à tradição romântica, denunciando-Ihes exatamente a face de distorção, por conta das influências externas, daquilo que seria a verdadeira vitalidade do nacional. Defendendo uma arte liberta da imitação da natureza, põe em destaque uma via de construção do nacional em sintonia com as conquistas da cultura e não ditada por uma eterna submissão à natureza e às visões cristalizadas do popular, ainda ditadas pela moldura do olhar europeu, contra as quais seu projeto de afirmação livre do Brasil deve se insurgir:

Destruo toda essa literatura acadêmica, romântica, literatura que só é literatura e não vida e energia. Construo com o granito, com o ferro, com a madeira, que a terra pródiga me oferece, a morada simples, clara, forte, graciosa do brasileiro. Ergo os palácios, as fábricas, as estações, os galpões, não copiando as nossas florestas, os nossos montes, mas com a força dinâmica libertadora do espírito moderno, que cria coisa própria. Recolho a língua do meu povo e transformo a sua poesia em poesia universal. Faço da minha atualidade a forja do futuro (In: TELES: 1985, pp. 324-5).

Era um anúncio compassado com o espírito desconstrutor e reconstrutor, que agressivamente queria dominar a cena, em uma clara desestabilização dos signos consagrados da nação, em suas formas de poder institucionalizadas. No "Manifesto da Poesia Pau-Brasil", Oswald revela essa disposição inequívoca, na crítica ao "lado doutor", advindo de uma tradição em que o jugo foi regra ("Eruditamos tudo. Esquecemos o gavião de penacho."), e a inversão das direções no fluxo cultural aponta a su- 
peração: "A única luta - a luta pelo caminho. Dividamos: Poesia de importação. E a Poesia Pau-Brasil, de exportação".

$\mathrm{Na}$ verdade, para o intuito de construir uma unidade - vista como fundamental para o combate a um arraigado tradicionalismo -, essa atitude mais agressiva talvez fosse, de fato, não só o caminho possível, como também aquele que melhor expressava a base comum a partir da qual, em seguida, iriam se dividir os modernistas, com seus diversos coloridos ideológicos, suas concepções artísticas e seus projetos para o Brasil. Mais ainda, o sentido de ataque articulado e coletivo "dos moços" ao peso da tradição parece mesmo ter sido fundamental para o alcance do que Francisco Iglésias chama de "eficácia histórica" da Semana, na construção de um marco significativo "no campo intelectual e com projeções no político" (In: ÁVILA: 1975, p.15).

O passadismo confesso de Mário no "Prefácio", contudo, não constituía nota solitária. Ainda que, à primeira vista, com menor força de choque do que as bandeiras da libertação do lirismo, da revolução estética e da atualização, o fenômeno artístico do Modernismo trazia um intenso esforço de compreensão do passado, liberto das convenções que até então o haviam aprisionado, numa cadeia de simbologias e semióforos pacificadores.

Em "A escrava que não é Isaura", publicado em 1924, Mário de Andrade declara "o amor esclarecido ao passado" como uma das forças que regem a nova Poesia, para além do propagandismo de Marinetti . Embora se trate de uma posição conhecida do poeta da Paulicea face à identificação imprecisa (de futurista) que em dado momento Ihe foi atribuída, sua relação com o passado demonstrou muito mais vitalidade que essa reação, em si mesma datada e atrelada àquelas circunstâncias específicas. 0 movi- mento intelectual que marcou a trajetória desse escritor e estudioso foi o de busca do Brasil, de seu folclore e tradições populares, a pesquisa da expressão artística brasileira, inclusive com a redescoberta do Barroco mineiro - elementos que o acompanharam pela vida, tornando-se matéria ficcional e objeto de elaboração crítica. Nesse sentido, é também significativa e mesmo emblemática a expedição que alguns dos protagonistas da geração de 22 realizaram pelas cidades históricas de Minas Gerais.

Sob o manto mais propagandeado de rejeição do passado, abriga-se, na verdade, uma trilha de redescoberta seletiva da história, em grande parte na contramão daquilo que encobrisse as relações de poder e as fraturas dos projetos das elites brasileiras desde os tempos coloniais. Essa via, por sua vez, compunha o intenso impulso de interpretação do país que marcou toda uma geração de intelectuais do período, na arte, na política, na antropologia ou nas ciências sociais. Dela participam nomes importantes - como Oliveira Viana, Gilberto Freyre, Paulo Prado, Sérgio Buarque de Hollanda - que marcaram sua época e levantaram questões que ainda seguiriam sendo debatidas por longo tempo.

Antonio Candido estabelece importante relação entre esse impulso e o pendor ensaístico do período:

É característico dessa geração o fato de toda ela tender para o ensaio. Desde a crônica polêmica (arma tática por excelência, nas mãos de Oswald de Andrade, Mário de Andrade, Ronald de Carvalho, Sérgio Buarque de Hollanda), até o longo ensaio histórico e sociológi$\mathrm{co}$, que incorporou o movimento ao pensamento nacional, - é grande a tendência para a análise. Todos esquadrinham, tentam sínteses, procuram explicações. Com o recuo do tempo, vemos agora que se tratava de redefinir a nossa cultura à luz de uma avaliação nova dos seus 
fatores. Pode-se dizer que o Modernismo veio criar condições para aproveitar e desenvolver as intuições de um Sílvio Romero, ou um Euclides da Cunha, bem como as pesquisas de um Nina Rodrigues (CANDIDO: 1980, p. 123).

E o período em que esse esforço interpretativo se desenvolveu é de acirramento das contradições e de uma crise republicana cuja face mais evidenciada, até pelas decorrências que traria ao cenário político, é o tenentismo. A relação que se pode estabelecer entre as duas esferas - da produção intelectual e daquele movimento políticomilitar -, embora não orgânica ou direta, revela muito da turbulência da época. Francisco Iglésias analisa o sentido e as dissonâncias dessa geração, apontando que nela artistas e setores médios da sociedade (particularmente os tenentes) podem ser genericamente agregados como "geração de 22", uma vez que a eles se colocavam questões prementes, comuns em uma experiência social e artística de submissão ou tutela.

Para ele (como para outros vários historiadores), "o Modernismo e o Tenentismo surgem da insatisfação dominante". O primeiro, "ante a estagnação ou mesmo realidade retrógrada, que vive de academismos, de culto à gramática e de regras, literatura e artes submetidas a padrões europeus, sem criatividade" (in: ÁVILA: 1975, p. 21). O segundo, defendendo uma "posição nacionalista" e contra as oligarquias, "a favor de forte governo central, que federalizasse a justiça e as polícias estaduais" (idem, ibidem). É significativa ainda a estreita ligação que 0 historiador estabelece entre 22 e a Independência. Baseando-se em Ortega $Y$ Gasset - que expõe como um dos critérios definidores de uma "geração" a existência de um fato histórico capaz de criar estado de consciência -, afirma Iglésias:
(...) a Independência é fato histórico capaz de criar estado de consciência. Cem anos depois da emancipação política, o homem brasileiro podia perguntar se de fato o país se tornara livre, se não lhe pesavam algumas tutelas. Perguntar, sobretudo, o que havia feito ao longo de cem anos, no sentido de realizar a nação, explorando suas potencialidades e incorporando toda a população em uma sociedade aberta e democrática (idem, p. 20).

A geração de 22 encontrava - diante da mesma ressonância histórica da Independência - o acúmulo das desigualdades e uma conjuntura distinta, que atestava, em grande escala, a potencial falência das promessas do liberalismo:

A idéia de "civilização ocidental" passava por uma fase de descrédito, pois sua perspectiva de construção do progresso, tão enfatizada pelas ideologias evolucionistas do século XIX, havia conduzido os estados europeus à barbárie da guerra e à ameaça de movimentos políticos totalitários (VELOSO \& MADEIRA: 1999, pp. 95-6).

Essa fase de descrédito ainda contava com um novo elemento, advindo do crescimento urbano e industrial do Brasil no início do século XX - circunstância inexistente no país agrário da independência: a formação de um proletariado. Núcleo de importantes mobilizações internas no início do século, os movimentos de trabalhadores, inicialmente de colorido anarquista, ressoava em um clima de questionamento da ordem vigente, para o qual contribuía também, embora com orientação política distinta, a insatisfação das camadas médias da sociedade.

Se considerarmos que os protagonistas da Semana, a exemplo dos românticos, tinham origem social nas classes dominan- 
tes ou entre elas possuíam livre circulação (cf. CANDIDO: 1980), está claro que um conjunto de fatores e de novos atores sociais trouxe-lhes uma possibilidade de diálogo e de referência impensável para os intelectuais que se houveram com as questões da brasilidade no período pós-independência. Estavam certos os modernistas, quando identificavam os limites que teriam as formas literárias de Casimiro e Alencar frente a uma nova realidade que se fazia cada vez mais complexa, no Brasil em franco crescimento urbano, desejoso de cosmopolitismo, e de todo modo ainda subalterno, no conturbado cenário mundial do início do século XX.

E a complexidade dessa nova cena social brasileira há de se manifestar nos próprios desdobramentos da Semana em torno do projeto, simultaneamente estético e político, para a representação artística da nação. É na disputa de rumos, presente na vida social, que também se inscrevem os polarizados caminhos dos grupos identificados com o verdeamarelismo e com a antropofagia, seguindo, de fato, vias muito diferenciadas, em um debate que sorvia o acirramento próprio da época, rumo à crise de 29. Afinal, a centralidade da questão nacional no período do entreguerras não é um fenômeno somente brasileiro, mas antes uma preocupação que domina o cenário ocidental e ajuda a delinear algumas das forças ativas da disputa que será retomada, em proporções ainda maiores, com a Segunda Guerra.

Será, enfim, desse fervilhar de posições e atitudes, característico do período de instabilidade e grandes transformações, postas para a vida social e cultural do início do século $X X$, que se vai desdobrar uma reflexão mais profunda e permanente sobre a questão nacional. Revelando diversas orientações na interação com o contexto de acirrado enfrentamento de projetos, a con- quista de uma forma de "consciência criadora nacional" (nas palavras de Mário) vai, ao longo de todo o século XX e ainda hoje, dialogar com as contradições da tradição moderna em que se inserem as próprias nacionalidades.

Da mesma maneira que os cem anos decorridos em relação à independência trouxeram, para os intelectuais e escritores da geração de 22, a pergunta sobre o que se fizera do Brasil, também hoje a questão ainda parece ter lugar garantido. De fato, perguntar sobre o que se fez ao longo desses outros quase cem anos decorridos daquele centenário e sobre o que se poderia fazer para a construção de um Brasil diferente, é, em nossos dias, tarefa presente na sociedade e também para a arte.

\section{REFERÊNCIAS BIBLIOGRÁFICAS:}

ANDRADE, Mário. Aspectos da literatura brasileira. $5^{\mathrm{a}}$ ed. São Paulo: Martins, 1974.

ANDRADE, Oswald. Ponta de lança. São Paulo: Globo, 1991.

ÁVILA, Affonso (org.). O modernismo. São Paulo: Perspectiva, 1975.

BOSI, Alfredo. História concisa da literatura brasileira. São Paulo: Cultrix, 1985.

BRITO, Mário da Silva. História do Modernismo brasileiro: antecedentes da Semana de Arte Moderna. $4^{a}$ ed. Rio de Janeiro: Civilização Brasileira, 1974.

BRASIL. Orientações Curriculares para 0 Ensino Médio: Linguagens, Códigos e suas Tecnologias. Brasília: MEC/SEB, 2006.

CANDIDO, Antonio. Literatura e sociedade: estudos de teoria e história literária. 
$6^{\mathrm{a}}$ ed. São Paulo: Ed. Nacional, 1980.

KRAMER, Sônia. Leitura e escrita como experiência - notas sobre seu papel na formação. In: ZACUR, Edwiges

(org.). A magia da linguagem. Rio de Janeiro: DP\&A/SEPE,1999.

TELES, Gilberto Mendonça. Vanguarda europeia e modernismo brasileiro: apresentação dos principais poemas manifestos, prefácios e conferências vanguardistas, de 1857 a $1972.7^{a}$ ed. Petrópolis: Vozes, 1983.

VELOSO, Mariza \& MADEIRA, Angélica. Leituras brasileiras. Itinerários no pensamento social e na literatura. Rio de Janeiro: Paz e Terra, 1999. 